\title{
Environmental determinants of foraging strategies in Cory's shearwaters Calonectris diomedea
}

\author{
Joan Navarro ${ }^{1,2, *}$, Jacob González-Solís ${ }^{1}$ \\ ${ }^{1}$ Departament de Biologia Animal (Vertebrats), Facultat de Biologia, Universitat de Barcelona, Av. Diagonal 645, \\ Barcelona 08028, Spain
}

${ }^{2}$ Present address: Department of Conservation Biology, Estación Biológica de Doñana EBD-CSIC, Av. Américo Vespucio, s/n, 41092 Sevilla, Spain

\begin{abstract}
Despite the advent of devices to track seabird movements, the extent to which productive areas and oceanic winds influence foraging strategies is still not fully understood. We investigated the main environmental determinants of foraging strategies in Cory's shearwaters Calonectris diomedea by combining satellite-tracking information from 14 birds breeding on the Canary Islands with concurrent data on chlorophyll a ( $\mathrm{chl}$ a) concentrations and oceanic winds. Additionally, we took blood samples at the end of each foraging trip and analysed carbon $(\mathrm{C})$ and nitrogen $(\mathrm{N})$ stable isotopes to examine the use of trophic resources. All birds showed commuting trips, concentrating foraging activity exclusively on the African continental shelf. Foraging locations showed a strong association with chl a concentrations, suggesting birds select foraging areas according to prey availability. In contrast with other breeding colonies where Cory's shearwaters use a dual-foraging method, birds showed a unimodal strategy and did not show differences in $\mathrm{C}$ and $\mathrm{N}$ isotope signatures in plasma, confirming that close proximity to highly productive areas strongly influences foraging strategies. In addition, birds tracked during 2 consecutive trips foraged in the same area, suggesting that high resource availability promotes fidelity to feeding grounds also at coarse scales. Persistent northeast trade winds blew during the study period, and commuting trips followed a consistent clockwise movement with a southwest heading while the birds foraged along the continental shelf, suggesting that birds used tail winds to reduce their flying costs. Our results corroborate that oceanographic conditions in the vicinity of the breeding colony have a strong effect on foraging strategies of pelagic seabirds.
\end{abstract}

KEY WORDS: Chlorophyll a · Foraging movements $\cdot$ Oceanic productivity $\cdot$ Oceanic wind $\cdot$ Satellite tracking $\cdot$ Stable isotopes $\cdot$ Canary Islands

\section{INTRODUCTION}

Pelagic seabirds often use as feeding grounds areas with high primary productivity, such as upwelling shelves or fronts and eddies (Croxall \& Wood 2002, Weichler et al. 2004, Louzao et al. 2006, Vilchis et al. 2006). However, these areas are patchily distributed and their accessibility can be limited by their remoteness or by environmental factors. This can be particularly critical for seabirds when breeding duties restrict foraging movements to the vicinity of the colony (Rick- lefs 1983, Brooke 2004). Isolated islands where seabirds can breed are often far from these areas, forcing parents to balance among reaching productive areas, sharing incubation tasks or providing enough food to the chick and maintaining their own body condition. As a result, pelagic seabirds have evolved specific foraging strategies mainly related to the distance, predictability and accessibility of resources (Granadeiro et al. 1998b, Waugh et al. 2000, Baduini \& Hyrenbach 2003).

Distance from the breeding colony to productive areas may determine unimodal or bimodal distribu- 
tions in the length of the foraging trips. Birds use a dual-foraging strategy when local resources are poor, combining short trips (1 to $3 \mathrm{~d}$ duration) in near-colony waters for chick provisioning, with longer trips ( $>5 \mathrm{~d}$ duration) to distant but highly productive areas for self-provisioning (Weimerskirch 1998, Baduini \& Hyrenbach 2003, Congdon et al. 2005, Magalhães et al. 2008). However, in breeding colonies close to productive areas we would expect seabirds to rely on local resources and provision their chicks using a unimodal strategy (Granadeiro et al. 1998b, Waugh et al. 2000, Baduini \& Hyrenbach 2003).

Spatial and temporal predictability of the trophic resources can modulate foraging-site fidelity. To optimize foraging performance, seabirds learn where and when resources are distributed within their potential foraging range and may return to the same feeding grounds during successive trips (Fernández et al. 2001, Weimerskirch 2007). In areas where resources are highly predictable, such as continental shelves or productive fronts, we expect fidelity to increase (Irons 1998, Hamer et al. 2001, Watanuki et al. 2003, Weimerskirch 2007).

Foraging movements of birds and the accessibility to feeding areas can be mediated by the strength and direction of oceanic winds (Spear \& Ainley 1997, Weimerskirch et al. 2000, Shaffer et al. 2001, Phillips et al. 2004). Although birds can fly in any direction, travelling against strong head winds is challenging because these are of the same order of magnitude as the bird airspeed (Liechti 2006). This is particularly true for seabirds, because while the lack of barriers in the marine environment can make possible unrestricted aerial movements, this same lack of barriers allows stronger, unobstructed winds. For example, petrels usually fly with cross winds and, hence, are forced to make more efficient use of the wind when foraging over wide ocean expanses (Weimerskirch et al. 2000). Winds can even shape the distribution of seabirds at sea, eventually promoting spatial segregation by species (Spear \& Ainley 1998, González-Solís et al. 2008) and spatial segregation by sexes (Shaffer et al. 2001). Therefore, we can expect seabirds to take into account oceanic winds in designing foraging trips as well as correcting movements according to wind direction and speed.

We can test these hypotheses by tracking the movements of pelagic seabirds at similar spatial and temporal scales to those used by oceanographers to characterise the biophysical traits of the sea surface. Combining the analysis of tracked movements with marine productivity or oceanic winds allow us to better understand why seabirds feed on specific areas and how they modulate foraging behaviour and follow particular paths (Weimerskirch et al. 2000, Louzao et al.
2006, Felicísimo et al. 2008). In addition, we can relate foraging behaviour with trophic resources through the analysis of stable isotopes of nitrogen (N) and carbon (C) in blood plasma. Due to its rapid turnover, plasma integrates prey captured in the last foraging trip (Hobson \& Clark 1993, Cherel et al. 2005). N signatures indicate trophic level of the diet, whereas $\mathrm{C}$ signatures can indicate the primary sources of C (Hobson 1999, Forero \& Hobson 2003)

The main objective of the present study was to investigate the environmental determinants of foraging strategies in the Cory's shearwater Calonectris diomedea, a pelagic seabird. Specifically, our aims were (1) to test whether birds choose their feeding grounds according to oceanic productivity, (2) to examine whether the occurrence of high productive areas relatively close to breeding colonies influences foraging strategies, according to the above predictions regarding unimodal and dual-foraging strategies and feeding ground fidelity, and (3) to examine the potential relationship between the direction of oceanic winds and foraging routes.

\section{MATERIALS AND METHODS}

Study species. Cory's shearwater is a long distance migrant and a colonial petrel that breeds in the northeast Atlantic and on Mediterranean islands. It is a medium-sized petrel species, with a body mass of $0.810 \pm 0.07 \mathrm{~kg}$ for males $(\mathrm{n}=55)$ and $0.716 \pm 0.05 \mathrm{~kg}$ $(\mathrm{n}=44)$ for females, and a wingspan of $1.26 \pm 0.03 \mathrm{~m}$ for males and $1.23 \pm 0.02 \mathrm{~m}$ for females (authors' unpubl. data, all measurements mean \pm SD). The species shows a high reproductive investment (8 mo), long incubation (54 d) and chick-rearing (90 d) periods and a life span of more than $30 \mathrm{yr}$. The 2 members of a mating pair share the chick-rearing tasks. Birds return to the nest only at night for chick provisioning (for more details see Thibault et al. 1997). During breeding, the parents primarily feed on areas situated hundreds of kilometres from their breeding site (Mougin \& Jouanin 1997, Navarro et al. 2007). Their diet is mainly composed of epipelagic fish and squid (Granadeiro et al. 1998a), which are usually abundant in upwelling shelves and productive oceanic regions (Garibaldi \& Limongelli 2002, FAO 2003).

Breeding and foraging grounds. We conducted the study on Gran Canaria Island (Canary Islands, $15^{\circ} 47^{\prime} 18^{\prime \prime} \mathrm{N}, 27^{\circ} 50^{\prime} 41^{\prime \prime} \mathrm{E}$, Fig. 1) during the chickrearing period (September 2005) at a breeding colony of about 150 pairs of Cory's shearwaters. The Canary Islands are a volcanic archipelago characterized by abrupt bathymetry with a profile that rises sharply from depths over $2000 \mathrm{~m}$ to narrow island shelves 

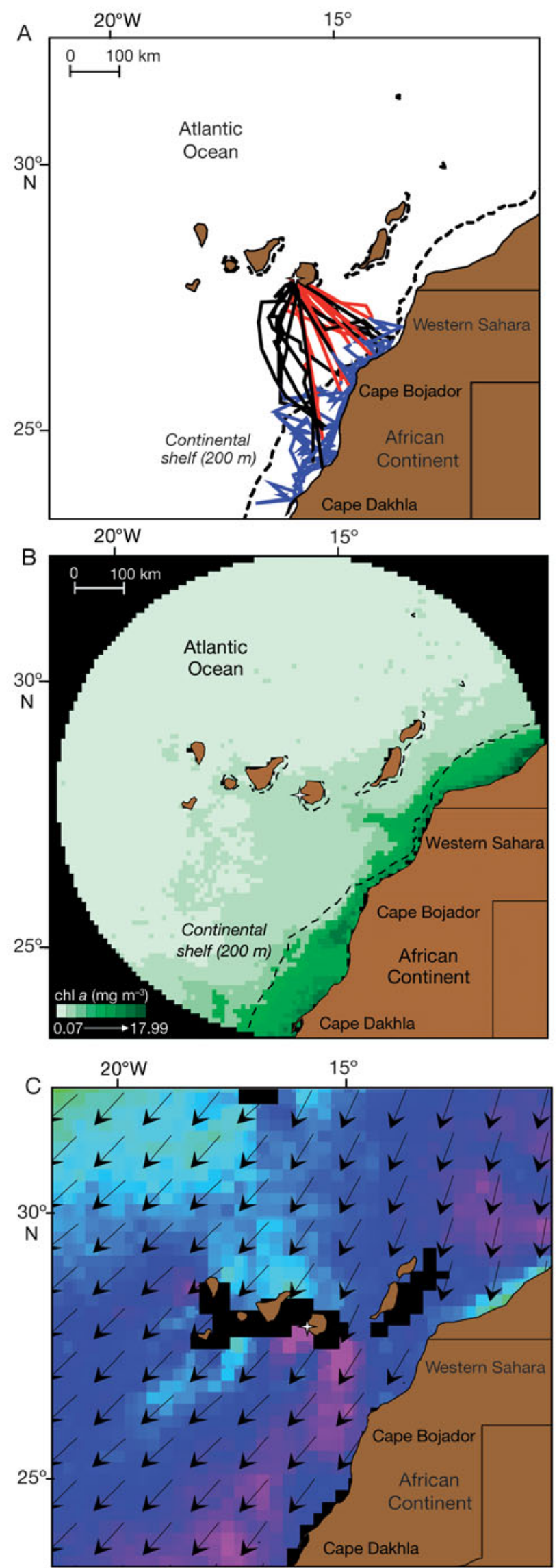

heavily influenced by oceanic conditions. This archipelago is located in the NE Atlantic Ocean, near the Canary Current, one of the major productive regions of the world. The Canary Current upwelling process is well understood; equatorial trade winds along Western Africa lead to an offshore transport of surface water and subsequent upwelling of cold, nutrient rich waters over the continental shelf (Longhurst 1998, Davenport et al. 2002). This environment provides fertile conditions for zooplankton production and the development of relatively diverse and abundant populations of epipelagic fish, such as different clupeids species (Garibaldi \& Limongelli 2002, Arístegui et al. 2006).

Fieldwork and laboratory procedures. To examine foraging movements, we tracked 14 breeding birds ( 7 males and 7 females) from different nests using Platform Terminal Transmitters (PTTs) during 1 foraging trip. Additionally, we tracked 2 consecutive foraging trips in 4 birds ( 2 males and 2 females) to determine foraging-site fidelity. The PTTs weighed $18 \mathrm{~g}$ and had a $60 \mathrm{~s}$ transmission cycle (Bird Borne from North Star Science and Technology). The weight of the PTTs was less than the $3 \%$ suggested by Phillips et al. (2003) to avoid detrimental effects (see Magalhães et al. 2008 for Cory's shearwater). At the end of the foraging trip all tracked birds and 14 control birds were bled for biochemical analyses of plasma. None of the parameters analysed relating to muscular damage and nutritional state (triglycerides, cholesterol, uric acid, urea, creatine kinas and lactate dehydrogenase) showed significant differences between the 2 groups (results not shown), suggesting no detrimental effects of the PTT on the tracked birds. We captured birds at their nests after chick feeding, attached the PTTs and released them at their nests. We attached the PTT to the middorsal feathers of the mantle using $\mathrm{Tesa}^{\odot}$ tape (Wilson \& Wilson 1989).

To examine the relationships between foraging activity and trophic ecology, we took $1 \mathrm{ml}$ of blood and weighed 10 birds at the end of their foraging trip. Blood was transferred to a vial containing dry lithium heparin and stored at 2 to $4^{\circ} \mathrm{C}$ until centrifugation. After 10 min of centrifugation at $5500 \times g$ we used the plasma to determine stable isotope ratios of nitrogen $\left(\delta^{15} \mathrm{~N}\right)$ and carbon $\left(\delta^{13} \mathrm{C}\right)$. See Navarro et al. (2007) for stable isotope procedures.

Fig. 1. Calonectris diomedea. (A) Foraging trips of 14 satellitetracked Cory's shearwaters. Line colours indicate the outward (red), feeding (blue) and inward (black) trajectory. (B) Chl a concentrations during chick-rearing period (September 2005) in a radius of $480 \mathrm{~km}$ from the breeding colony. (C) Average wind direction and speed for the same area and period. Wind speed is colour-coded from fuchsia $\left(0 \mathrm{~m} \mathrm{~s}^{-1}\right)$ to green $\left(6 \mathrm{~m} \mathrm{~s}^{-1}\right)$, and arrows show wind direction. White star indicates the breeding colony location 
Data processing, environmental variables, and statistical analyses. Data on the position of the PTTs were obtained from the ARGOS system (cycle programmed in $15 \mathrm{~min}, 10 \mathrm{~km}$ resolution data) and were processed using ArcView GIS 3.2 program (Hooge et al. 1999). Following previous authors (e.g. Magalhães et al. 2008), we used only data of Class A or better to examine foraging locations obtained from the ARGOS system. In addition, we removed those positions with a movement rate (velocity) above $50 \mathrm{~km} \mathrm{~h}^{-1}$ as defined by the ratio between distance covered and time elapsed between 2 positions. These procedures filtered up to $10 \%$ of the uplinks per trip. We calculated trip distance and trip duration as the sum of distances and time durations between consecutive positions over the complete trip, respectively. We calculated the foraging range as maximum distance covered from the breeding colony and the average speed as the ratio between trip distance and trip duration.

To determine the relationship between feeding grounds and marine productivity, we examined the relationship between foraging locations obtained from the tracked birds and sea surface chlorophyll a (chl a) concentration, a measure of phytoplankton standing stock (Miller 2003). For this purpose, using data from the SeaWiFS project (http://oceancolor.gsfc.nasa.gov/ SeaWiFS/), we first calculated mean chl a concentrations during our study period (September 2005) in each $10 \times 10 \mathrm{~km}$ square area within a $480 \mathrm{~km}$ radius of the breeding colony, as defined by the maximum distance reached by the foraging birds during the study period. There were $5289 \mathrm{chl}$ a values available for this area from SeaWiFS. All tracked shearwaters had commuting trips, therefore visual analysis allowed us to divide each trip into a departing, foraging and returning portion (Fig. 1, red, blue and black lines, respectively). Then we obtained the chl a concentration value of the $10 \times$ $10 \mathrm{~km}$ square corresponding to the mean foraging position for each bird, which was obtained by averaging the foraging positions of the foraging portion of the trip. Final mean chl a concentration value for all foraging areas was obtained by averaging the value of all birds.

We used re-sampling procedures to test the relationship between chl a concentration values and the location of the foraging areas. These procedures evaluate the likelihood of obtaining equal or greater chl a values than that obtained for the mean foraging position of the birds $\left(1.69 \mathrm{mg} \mathrm{m}^{-3}\right)$. First, the core procedure consists of averaging 14 random samples of chlorophyll values (with replacement) from among the 5289 potential values in the study area. Second, we repeated this procedure 10000 times. Third, among the 10000 simulations, we calculated the proportion of values equal to or greater than those obtained for the birds $\left(1.69 \mathrm{mg} \mathrm{m}^{-3}\right)$. Finally, to consider 2-tailed proba- bility, we calculated the p-value for the mean chl a value corresponding to the foraging birds as the duplicate of the above-mentioned proportion.

To determine whether birds showed foraging-site fidelity, we first calculated the geometric distance between the centroids of the feeding areas covered during both consecutive trips of tracked birds. Assuming that all distances were equally likely between the centroids of any combination of 2 trips, we obtained an empirical distribution function by taking 10000 random samplings of four 2-trip distances from the 28 possible combinations (among the 8 centroides). Significance of the association between 2 consecutive trips of the same bird was tested by calculating the 2-tailed probability in the obtained empirical distribution defined by the mean value of the 2 consecutive trips of the 4 birds.

To examine the relationship between sea surface winds and foraging movements, we first estimated whether the direction of the foraging movements in relation to that of the oceanic winds followed a consistent pattern. To test directionality of birds and winds, we first calculated individual travel directions at departure (departing portion, Fig. 1, red line), during foraging (foraging portion, Fig. 1, blue line) and at return (returning portion, Fig. 1, black line), as well as the direction of the oceanic wind in the area during each foraging trip and the average direction over the entire study period (September 2005, n = 30 d). Directionality was tested using the Rayleigh's uniformity test and the association between wind direction and trip direction was tested using the Watson-Williams F-tests (Zar 1984). To establish each foraging trip portion we analysed the ranging behaviour of each tracked bird (e.g. departing portion ends when the distance to the colony stops increasing, see Stahl \& Sagar 2006). Data of the direction of the oceanic winds was obtained from the Sea-Winds database (http://winds. jpl.nasa.gov). Moreover, we examined differences among the movement rate during departing, foraging and returning portions of the trips using a repeated-measures ANOVA. To detect differences among trip portions we applied a post-hoc $t$-test using the Bonferroni correction.

To examine the relationships between trip traits and trophic ecology, we correlated foraging descriptors (trip duration, foraging range, trip distance and movement rate) with stable isotopes signatures of $\mathrm{N}$ and $\mathrm{C}$ using Pearson's correlation coefficient (Zar 1984). To test if the frequency of the foraging trip duration was uni- or bimodal we applied the Shapiro-Wilks test. We used Oriana 2.0 software (Kovach Computing Services 2006) to perform the Rayleigh's and Watson-Williams F-tests. We analysed spatial data with MiraMon (Pons 2000) and Animal Movement Extension for ArcView GIS 3.2 (Hooge et al. 1999). 


\section{RESULTS}

All satellite-tracked birds foraged exclusively on the continental shelf (200 m depth) located off Western Africa, between Cape Bojador and Cape Dakhla (Fig. 1A, Western Saharan coast). Foraging locations showed a highly significant association with elevated chl a concentrations ( $\mathrm{p}<0.001)$. Trip duration ranged from 2.25 to $6.75 \mathrm{~d}(4.34 \pm 1.46 \mathrm{~d}$, mean $\pm \mathrm{SD})$ and its distribution did not depart significantly from a normal unimodal distribution (Shapiro-Wilks, $Z=0.91, \mathrm{p}=$ 0.11, $\mathrm{n}=17$, Fig. 2). Total distance covered ranged from 445.87 to $1749.38 \mathrm{~km}(875.16 \pm 364.31 \mathrm{~km})$. Centroids of the foraging areas between 2 consecutive trips for the 4 birds tracked twice were, on average, $41.94 \mathrm{~km}$ apart, ranging from 11.42 to $68.85 \mathrm{~km}$ (Fig. 3). In contrast, mean of the 10000 selections on 4 random distances (between any 2 centroids) from the 28 possible distances was $142.73 \mathrm{~km}$. The probability that 4 random distances averaged by chance $41.94 \mathrm{~km}$ was $\mathrm{p}=0.0026$, indicating significant foraging-site fidelity between 2 consecutive trips.

In relation to the trajectories followed during the foraging trips, birds showed a consistent clockwise movement. Tracked birds consistently headed southeast and moved rapidly from the breeding colony to the African continental shelf (Figs. 1A, 4 \& 5A; mean movement rate $=11.91 \pm 2.47 \mathrm{~km} \mathrm{~h}^{-1}$, mean vector $=141.27^{\circ}$,

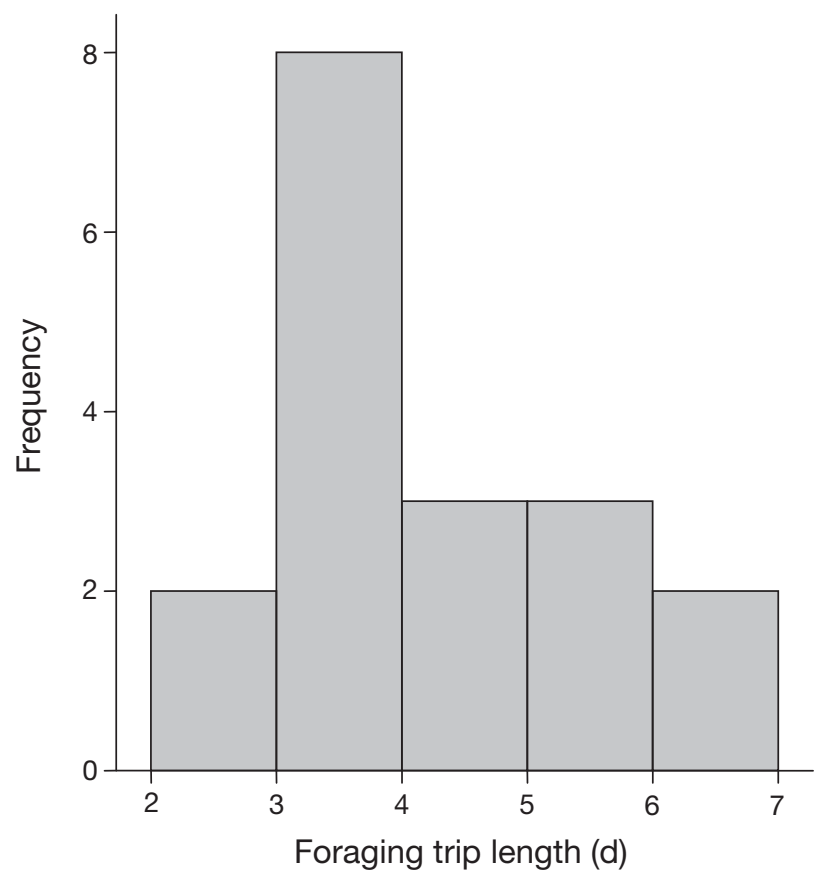

Fig. 2. Calonectris diomedea. Frequency distribution of foraging trip length for 18 satellite-tracked trips during the chickrearing period of Cory's shearwater breeding on Gran Canaria (Canary Islands)
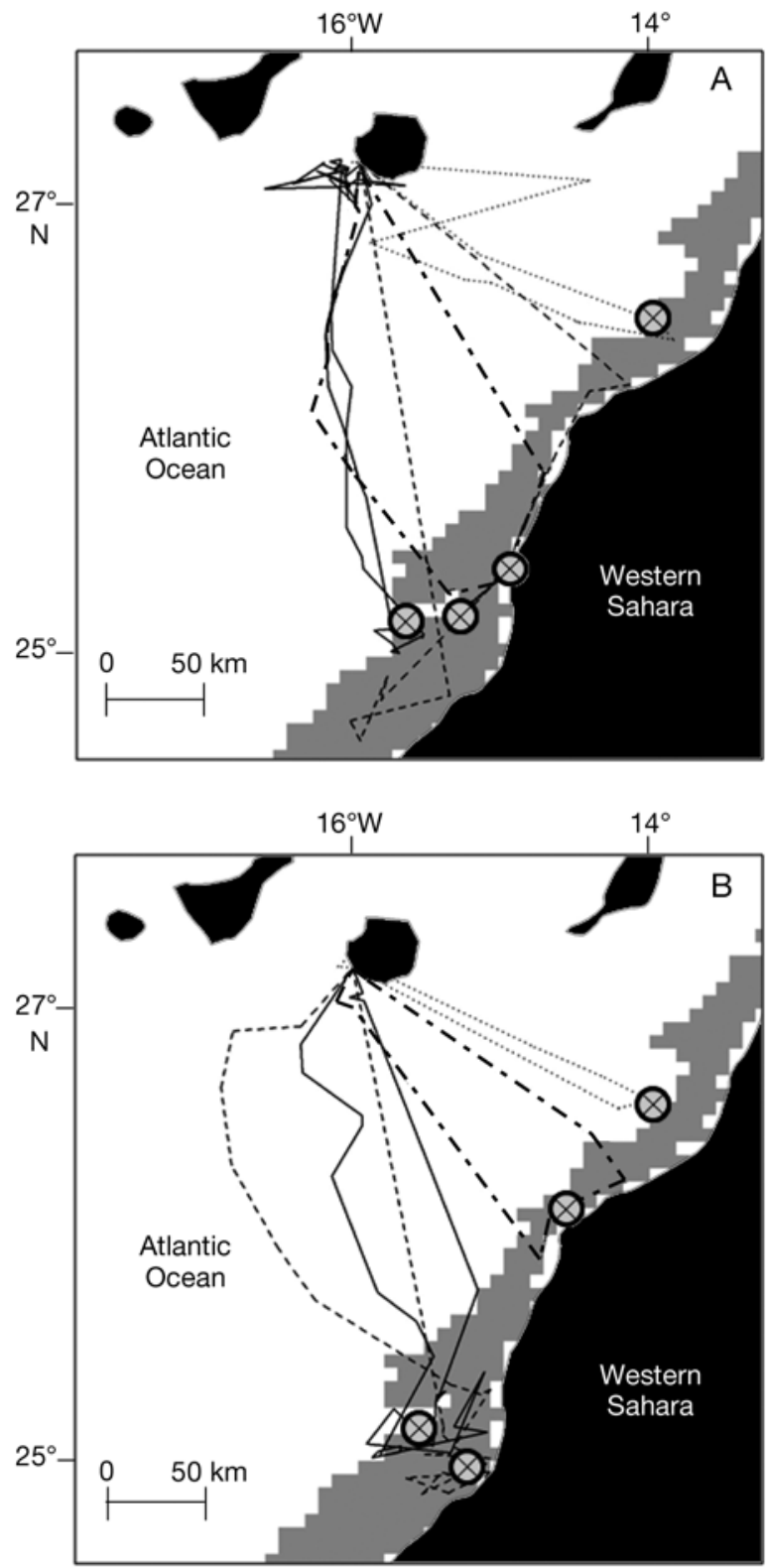

Fig. 3. Calonectris diomedea. Foraging movements of 4 Cory's shearwaters satellite-tracked in 2 consecutive trips: (A) first trip, (B) second trip. Each type of line indicates a different bird. Centroid of each foraging trip is indicated by $\otimes$. Grey area: high chl a area (ranging from 10.02 to $17.99 \mathrm{mg} \mathrm{m}^{-3}$ )

$\mathrm{r}=0.95, Z=12.64, \mathrm{p}<0.001)$. Once on the continental shelf, birds consistently headed southwest and moved slowly along the continental shelf (Figs. 1A, 4 \& 5B; mean movement rate $=5.98 \pm 2.75 \mathrm{~km} \mathrm{~h}^{-1}$, mean vector $=200.52^{\circ}, \mathrm{r}=0.51, Z=3.73, \mathrm{p}=0.02$ ). On the return trip, birds headed northeast and returned rapidly to the breeding colony (Figs. 1A, 4 \& 5C; mean movement rate $=11.58 \pm 3.46 \mathrm{~km} \mathrm{~h}^{-1}$, mean vector $=337.03^{\circ}$, 


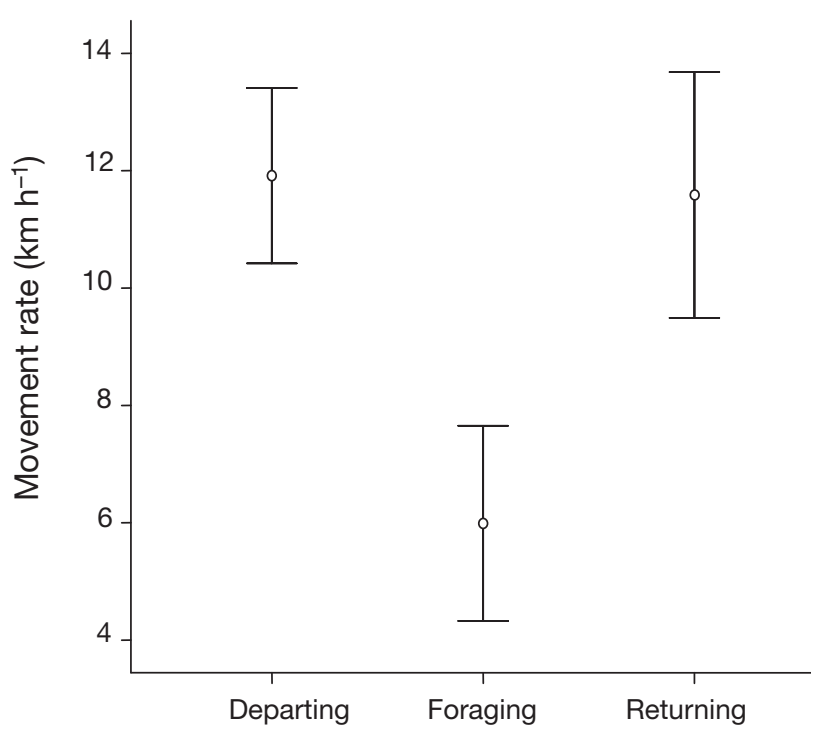

Fig. 4. Calonectris diomedea. Movement rate $\left(\mathrm{km} \mathrm{h}^{-1}\right)$ during departing, foraging and returning portion of 14 foraging trips of Cory's shearwaters satellite-tracked during the chickrearing period. Values are means $\pm 95 \%$ CI $\mathrm{r}=0.93, Z=12.22, \mathrm{p}<0.001)$. The movement rate while on the Western Sahara continental shelf was significantly lower than during either the departing or the returning portions of the trip (Fig. 4, $F_{2,12}=12.35$, $\mathrm{p}=0.002$ ). The return angle to the breeding colony was more northerly than the angle towards the feeding ground (Figs. 1A \& 5, Watson-Williams $F_{1,26}=216.34$, $\mathrm{p}<0.001)$. During the study period, sea surface winds consistently blew from the northeast (Figs. 1C \& 5D; mean vector $=207.8^{\circ}, \mathrm{r}=0.98, Z=29.99, \mathrm{p}<0.001$ ) and their heading did not differ with the direction followed by foraging birds along the continental shelf (Watson-Williams $F_{1,26}=0.04, \mathrm{p}=0.85$ ). In contrast, the direction of the prevailing wind was significant different to the direction of the departing (Watson-Williams $\left.F_{1,26}=126.07, \mathrm{p}<0.001\right)$ and the returning trajectories (Watson-Williams $F_{1,26}=362.13, \mathrm{p}<0.001$ ). Stable isotope signatures did not show any significant relationship with trip traits (plasma $\delta^{15} \mathrm{~N}=11.92 \pm 0.23$, plasma $\delta^{13} \mathrm{C}=-16.78 \pm 0.38$, Pearson's correlation, $\mathrm{p}>0.05)$
A
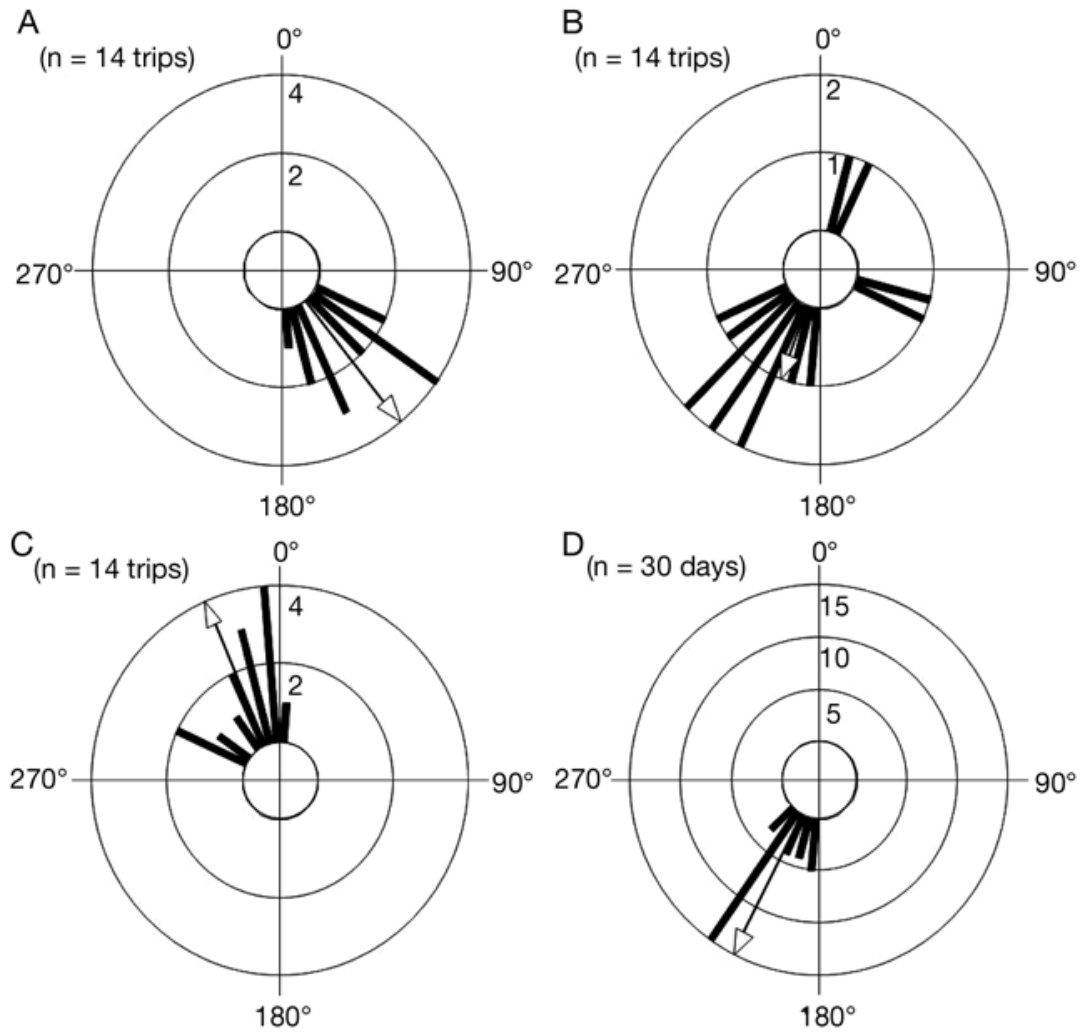

Fig. 5. Calonectris diomedea. Circular histograms of the directions taken by Cory's shearwater and that of the oceanic wind during the chick-rearing period (September 2005); (A) at departure to the feeding grounds, (B) along the Western Sahara coast, (C) at return to the breeding colony, (D) oceanic winds during the study period. Arrows indicate mean vector. Radial scale is: (A-C) no. of trips, (D) no. of days

\section{DISCUSSION}

All seabirds tagged showed commuting-type foraging trips, each of which could be easily divided into a rapid departing trajectory from the breeding colony to the African continental shelf, a slower and smaller-scale foraging movement usually parallel to the coast towards the southwest, and a rapid returning loop towards the breeding colony (Fig. 1A, red, blue and black lines, respectively). Despite the fact that birds could potentially search for food in any area within a $480 \mathrm{~km}$ radius from the breeding colony, all 14 birds concentrated foraging on a relatively small area located about $200 \mathrm{~km}$ from the breeding colony on the African continental shelf, specifically between Cape Bojador and Cape Dakhla (Fig. 1A, Western Saharan coast). Since the Canary Archipelago is volcanic and has a narrow shelf, high chl a concentrations within the $480 \mathrm{~km}$ radius of the breeding colony only occurred on the African continental shelf (Fig 1B). The strong meso-scale association (100 to $1000 \mathrm{~km}$ ) between foraging grounds and chl a concentrations suggests that Cory's shearwaters used this feeding ground because prey availability is 
greater and more predictable than in less productive areas also within their potential foraging range. Moreover, for the 4 birds tracked for 2 consecutive trips, the main foraging areas for both trips were coincident, indicating substantial foraging-site fidelity and suggesting that the African continental shelf has a high availability and predictability of prey at a coarse-scale (1 to $100 \mathrm{~km}$ ) (Fernández et al. 2001, Weimerskirch 2007). Indeed, the African continental shelf is under the influence of the Canary Current, one of the major upwelling ecosystems of the Atlantic Ocean, with high biological productivity (Longhurst 1998, Davenport et al. 2002) and thus sustaining abundant food for seabirds. However, a recent study on the spatial matchmismatch across 4 trophic levels of the Benguela upwelling zone found a strong correlation of gannet foraging areas to productive areas, but not to food availability, as indicated by anchovies and sardine densities (Gremillet et al. 2008). This result challenges the value of chl a concentrations and sea surface temperature as proxies for seabird food availability, but may be a consequence of the human overexploitation of fish stocks on that area and may not be applicable to other systems. Although no detailed data on epipelagic fish densities are available for the Western Africa continental shelf, several studies suggest that sardines and anchovies, the main prey also for Cory's shearwaters, are particularly abundant on this area (Garibaldi \& Limongelli 2002, Arístegui et al. 2006). Moreover, this area has been repeatedly cited as the main feeding ground for Cory's shearwaters breeding on the Canary Archipelago (Navarro et al. 2007, SEO/BirdLife unpubl. data) and on the Selvagens Islands (Mougin \& Jouanin 1997, F. Zino unpubl. data), and as the main wintering quarter for Cory's shearwaters breeding on Mediterranean colonies (González-Solís et al. 2007).

Dual foraging is a common strategy followed by many species of petrels during the chick-rearing period, including the Cory's shearwater (Granadeiro et al. 1998b, Baduini \& Hyrenbach 2003, Peck \& Congdon 2005, Magalhães et al. 2008). When local resources are poor, petrels use a specialised bimodal foraging strategy that alternates short trips in near-colony waters for chick provisioning with longer self-provisioning trips to highly productive areas located far away from breeding colonies (Weimerskirch et al. 1993, Weimerskirch \& Cherel 1998, Baduini \& Hyrenbach 2003, Cherel et al. 2005, Congdon et al. 2005). This seems to be the case for Cory's shearwaters breeding on the Azores, which engage in long foraging trips, up to $1800 \mathrm{~km}$ from the nest, that last for $20 \mathrm{~d}$ (Magalhães et al. 2008). To a lesser extent, this is also the case with Cory's shearwaters breeding on the Selvagens Islands, close to the Canary Islands, but still relatively far from the productive African continental shelf (about
$370 \mathrm{~km}$ ) (Mougin \& Jouanin 1997, Granadeiro et al. 1998b, Magalhães et al. 2008). Nevertheless, all Cory's shearwaters breeding on Gran Canaria foraged on the African continental shelf - which is only about 150 to $250 \mathrm{~km}$ from the breeding area and therefore within 2.25 to $6.75 \mathrm{~d}$ travel time - and showed a unimodal distribution. Moreover, as suggested by the absence of a relationship between $\delta^{13} \mathrm{C}$ and $\delta^{15} \mathrm{~N}$ signatures in plasma and the foraging descriptors, such as trip length, all birds apparently exploited the same trophic resources during the foraging trips. That is, similar $\delta^{13} \mathrm{C}$ signatures among tracked birds is consistent with all birds feeding on the same area, whereas $\delta^{15} \mathrm{~N}$ signatures reflected similar trophic level of the consumed prey (Cherel et al. 2005). Therefore, our results corroborate that pelagic seabirds breeding on islands close to a highly productive area provision their chicks using a unimodal strategy based on local productivity (Granadeiro et al. 1998b, Waugh et al. 2000, Baduini \& Hyrenbach 2003). In our study, the length of the trip is probably modulated by other factors, such as the previous time fasting on the nest or the difficulty to recover body condition during the foraging trip (Navarro \& González-Solís 2007).

It has been shown that foraging movements of large pelagic seabirds such as albatrosses, in windy areas such as the Southern Ocean, are influenced by the oceanic winds (Nicholls et al. 1997, Weimerskirch et al. 2000, 2002, Shaffer et al. 2001). However, studies on smaller petrels in calm subtropical waters are still scarce. Cory's shearwaters have long and slender wings adapted to combine gliding and active flight that, in theory, could be helped by oceanic winds to reduce flying costs (Rosén \& Hedenström 2001). This strategy has also been recently suggested for longdistance migratory movements in this species (Felicísimo et al. 2008). In the present study, satellite-tracked shearwaters showed a consistent clockwise trip movement. Most foraging movements on the continental shelf headed southwest $\left(200.52^{\circ} \mathrm{N}\right.$, Fig. 5B). Within this area, trade winds also blew consistently toward this direction during the study period $\left(207.08^{\circ} \mathrm{N}\right.$, Figs. 1C \& 5D). In theory, Cory's shearwaters may decide whether to forage with tail or head winds when on the continental shelf. However, the total agreement between the directions of winds and bird movement when foraging on the continental shelf, suggests the entire route of the foraging trip is optimized to avoid head winds and to use tail winds to reduce flying costs.

In contrast, Cory's shearwaters travelling from the breeding colony to the continental shelf and vice versa cannot choose their angle with respect to the northeast trade winds. Because of the inflexible origin (breeding colony) and destination (African continental shelf) of 
the trips and the consistency of trade winds over that period, birds must cope with cross, tail or head winds during departure or return trips, respectively. Therefore, differences in the wind angle with respect to the movement of the bird can affect the heading and shape of the departing and returning trips. Regarding the heading, the returning angle towards the breeding colony headed significantly further north than the departing angle towards the African continental shelf. However, this difference probably resulted from the more southern position of most birds on the continental shelf when returning to the colony, after foraging southwest with tail winds, rather than from the wind direction during the trip. On the contrary, the shape of the returning trajectory seems to be affected by the cross head wind, delineating a left loop that does not correspond to the shortest distance to the breeding colony nor to the outward route. This loop probably reflects the difficulty of birds to fully compensate their heading for the wind drift, since commuting trips are generally straight and follow the outward route (Weimerskirch 2007). Alternatively, because the Canary Islands act as a land barrier weakening wind strength on the southwest side of the islands (Fig. 1C), the loop of the returning trajectory may result from birds seeking the protection of the islands against head winds before heading to the colony.

Our study illustrates the strong influence of environmental factors on foraging strategies in a pelagic seabird. All tagged Cory's shearwaters exclusively foraged on a specific area within their potential foraging range, the African continental shelf. The strong association between the feeding locations and chl a concentrations, a proxy for phytoplankton standing stock and ecosystem structure, suggests that birds selected feeding grounds according to their prey availability, which promoted fidelity to a specific feeding grounds at meso- and coarse-spatial scales. Moreover, our results corroborate the notion that particular populations of species vary their foraging strategies depending on the distance to highly productive areas, showing a unimodal strategy when these areas are close to the breeding colony. Our study also shows that foragingtrip heading was influenced by oceanic winds, particularly when birds foraged on the continental shelf, suggesting that shearwaters avoid head winds, probably to reduce flying costs. In addition, the path of the return trip to the breeding colony suggests that Cory's shearwaters did not fully compensate for wind drift.

Acknowledgements. We thank B. Rodriguez and P. Arcos (SEO/BirdLife) for their field support; Y. Amescoa and P. Calabuig (Cabildo de Gran Canaria) for their logistical support; A. Felicísimo for his help with Fig. 5D; F. Sardá, R. Ramos, G. Viscor and 5 anonymous reviewers for their help in previous versions of the manuscript. J.N. was supported by a PhD grant of the Ministerio de Educación y Ciencia (MEC) of Spain and J.G.-S. was supported by a contract of the Program Ramon y Cajal of MEC and Fondos FEDER. Financial support was provided by the projects REN2002-01164 and CGL200601315/BOS from MEC, LIFE04ES/NAT/000049 from the European Commission and by the Fundación Banco Bilbao Vizcaya Argentaria. All methods used in this study complied with Spanish law.

\section{LITERATURE CITED}

Arístegui J, Alvarez-Salgado XA, Barton ED, Figueiras FG, Hernández-León S, Roy C, Santos AMP (2006) Oceanography and fisheries of the Canary Current/Iberian region of the eastern North Atlantic. In: Robinson AR (ed) The sea, Vol. 14B: The global coastal ocean: Interdisciplinary regional studies and syntheses. Harvard University Press, Cambridge, MA, p 877-931

Baduini CL, Hyrenbach KD (2003) Biogeography of Procellariiform foraging strategies: Does ocean productivity influence provisioning? Mar Ornithol 31:101-112

Brooke M (2004) Albatrosses and petrels across the world. Oxford University Press, Oxford

Cherel Y, Hobson KA, Weimerskirch H (2005) Using stable isotopes to study resource acquisition and allocation in procellariiform seabirds. Oecologia 145:533-540

> Congdon BC, Krockenberger AK, Smithers BV (2005) Dualforaging and co-ordinated provisioning in a tropical Procellariiform, the wedge-tailed shearwater. Mar Ecol Prog Ser 301:293-301

Croxall JP, Wood AG (2002) The importance of the Patagonian Shelf for top predator species breeding at South Georgia. Aquat Conserv Mar Freshwat Ecosyst 12:101-118

Davenport R, Neuer S, Helmke P, Perez-Marrero J, Llinas O (2002) Primary productivity in the northern Canary Islands region as inferred from SeaWiFS imagery. Deep-Sea Res 49:3481-3496

FAO (2003) Trends in oceanic captures and clustering of large marine ecosystems. 2 studies based on the FAO capture database. FAO Fish Tech Pap 435, Rome

Felicísimo AM, Muñoz J, González-Solís J (2008) Ocean surface winds drive dynamics of transoceanic aerial movements. PLoS One 3:e2928

Fernández P, Anderson DJ, Sievert PR, Huyvaert KP (2001) Foraging destinations of three low-latitude albatross species. J Zool (Lond) 254:391-404

Forero MG, Hobson KA (2003) Using stable isotopes of nitrogen and carbon to study seabird ecology: applications in the Mediterranean seabird community. Sci Mar 67:23-32

Garibaldi L, Limongelli L (2002) Trends in oceanic captures and clustering of Large Marine Ecosystems: two studies based on the FAO capture database. FAO Fisheries, Rome

Conzález-Solís J, Croxall JP, Oro D, Ruiz X (2007) Transequatorial migration and mixing in the wintering areas of a pelagic seabird. Front Ecol Environ 5:297-301

González-Solís JP, Croxall JP, Afanasyev V (2008) Offshore spatial segregation in giant petrels Macronectes spp: differences between species, sexes and seasons. Aquat Conserv Mar Freshw Ecosys 17:22-36

Granadeiro JP, Monteiro LR, Furness RW (1998a) Diet and feeding ecology of Cory's shearwater Calonectris diomedea in the Azores, north-east Atlantic. Mar Ecol Prog Ser 166:267-276

> Granadeiro JP, Nunes M, Silva MP, Furness RW (1998b) Flexible foraging strategy of Cory's shearwater, Calonectris diomedea, during the chick-rearing period. Anim Behav 56:1169-1176 
Gremillet D, Lewis S, Drapeau L, Der Lingen CD and others (2008) Spatial match-mismatch in the Benguela upwelling zone: Should we expect chlorophyll and sea-surface temperature to predict marine predator distributions? J Anim Ecol 45:610-621

Hamer KC, Phillips RA, Hill JK, Wanless S, Wood AG (2001) Contrasting foraging strategies of gannets Morus bassanus at two North Atlantic colonies: foraging trip duration and foraging area fidelity. Mar Ecol Prog Ser 224:283-290

Hobson KA (1999) Tracing origins and migration of wildlife using stable isotopes: a review. Oecologia 120:314-326

Hobson KA, Clark RG (1993) Turnover of ${ }^{13} \mathrm{C}$ in cellular and plasma fractions of blood: implications for nondestructive sampling in avian dietary studies. Auk 110:638-641

Hooge PN, Eichenlaub W, Solomon E (1999) The animal movement program. Alaska Biological Science Center, Anchorage, AK

Irons DB (1998) Foraging area fidelity of individual seabirds in relation to tidal cycles and flock feeding. Ecology 79: 647-655

Kovach Computing Services (2006) Oriana ver. 2.0. Kovach Computing Services, Pentraeth. Available at: www. kovcomp.co.uk

Liechti F (2006) Birds: blowin' by the wind? J Ornithol 147: 202-211

Longhurst A (1998) Ecological geography of the sea. Academic Press, San Diego, CA

Louzao M, Hyrenbach KD, Arcos JM, Abelló P, de Sola LG, Oro D (2006) Oceanographic habitat of an endangered Mediterranean procellariiform: implications for marine protected areas. Ecol Appl 16:1683-1695

Magalhães MC, Santos RS, Hamer KC (2008) Dual-foraging of Cory's shearwaters in the Azores: feeding locations, behaviour at sea and implications for food provisioning of chicks. Mar Ecol Prog Ser 359:283-293

Miller CB (2003) Biological oceanography. Blackwell Publishing, London

Mougin JL, Jouanin C (1997) Prospection alimentarie du puffin cendré Calonectris diomedea borealis de Selvagem Grande $\left(30^{\circ} 09^{\prime} \mathrm{N}, 15^{\circ} 52^{\prime} \mathrm{W}\right)$ pendant l'incubation, par télémétrie satellitaire. CR Acad Sci Ser III Sci Vie 320:825-831

Navarro J, González-Solís J (2007) Experimental increase of flying costs in a pelagic seabird: effects on foraging strategies, nutritional state and chick condition. Oecologia 151: $150-160$

> Navarro J, González-Solís J, Viscor G (2007) Nutritional and feeding ecology in Cory's shearwater Calonectris diomedea during breeding. Mar Ecol Prog Ser 351:261-271

Nicholls DG, Murray MD, Butcher E, Moors P (1997) Weather systems determine the non-breeding distribution of wandering albatrosses over southern oceans. Emu 97:240-244

Peck DR, Congdon BC (2005) Colony-specific foraging behaviour and co-ordinated divergence of chick development in the wedge-tailed shearwater Puffinus pacificus. Mar Ecol Prog Ser 299:289-296

Phillips RA, Xavier JC, Croxall JP (2003) Effects of satellite transmitters on albatrosses and petrels. Auk 120: 1082-1090

Phillips RA, Silk JRD, Phalan B, Catry P, Croxall JP (2004) Seasonal sexual segregation in the two Thalassarche albatross species: competitive exclusion, reproductive role specialization or foraging niche divergence? Proc R Soc Lond B Biol Sci 271:1283-1291

Editorial responsibility: Rory Wilson,

Swansea, UK
Pons X (2000) Miramon: Geographical information system and remote sensing software. Centre de Recerca Ecològica i Aplicacions Forestals (CREAF), Bellaterra

Ricklefs RE (1983) Some considerations on the reproductive energetics of pelagic seabirds. Stud Avian Biol 8:84-94

Rosén M, Hedenström A (2001) Testing predictions from flight mechanical theory: a case study of Cory's shearwater and Audouin's gull. Acta Ethol 3:135-140

Shaffer SA, Weimerskirch H, Costa DP (2001) Functional significance of sexual dimorphism in wandering albatross, Diomedea exulans. Funct Ecol 15:203-210

Spear LB, Ainley DG (1997) Flight behaviour of seabirds in relation to wind direction and wing morphology. Ibis 139: 221-233

Spear LB, Ainley DG (1998) Morphological differences relative to ecological segregation in petrels (Family: Procellariidae) of the Southern Ocean and Tropical Pacific. Auk 115:1017-1033

Stahl JC, Sagar PM (2006) Long and short trips in nonbreeding Buller's albatrosses: relationships with colony attendance and body mass. Condor 108:348-366

Thibault JC, Bretagnolle V, Rabouam C (1997) Cory's shearwater. Birds of the Western Paleartic (BWP) Update, Oxford University Press, Oxford

> Vilchis LI, Ballance LT, Fiedler PC (2006) Pelagic habitat of seabirds in the eastern tropical Pacific: effects of foraging ecology on habitat selection. Mar Ecol Prog Ser 315: 279-292

> Watanuki Y, Takahashi A, Sato K (2003) Feeding area specialization of chick-rearing Adelie penguins Pygoscelis adeliae in a fast sea-ice area. Ibis 145:558-564

Waugh SM, Weimerskirch H, Cherel Y, Prince PA (2000) Contrasting strategies of provisioning and chick growth in two sympatrically breeding albatrosses at Cambell Island, New Zealand. Condor 102:804-813

Weichler T, Garthe S, Luna-Jorquera G, Moraga J (2004) Seabirds distribution on the Humboldt Current in northern Chile in relation to hydrography, productivity, and fisheries. ICES J Mar Sci 61:148-154

Weimerskirch H (1998) How can a pelagic seabird provision its chick when relying on a distant food resource? Cyclic attendance at the colony, foraging decision and body condition in sooty shearwaters. J Anim Ecol 67:99-109

Weimerskirch H (2007) Are seabirds foraging for unpredictable resources? Deep Sea Res II 54:211-223

Weimerskirch H, Cherel Y (1998) Feeding ecology of shorttailed shearwaters: breeding in Tasmania and foraging in the Antarctic? Mar Ecol Prog Ser 167:261-274

Weimerskirch H, Salamolard M, Sarrazin F, Jouventin P (1993) Foraging strategy of wandering albatrosses through the breeding season: a study using satellite telemetry. Auk 110:325-342

Weimerskirch H, Guionnet T, Martin J, Shaffer SA, Costa DP (2000) Fast and fuel efficient? Optimal use of wind by flying albatrosses. Proc R Soc Lond B Biol Sci 267: 1869-1874

> Weimerskirch H, Bonadonna F, Bailleul F, Mabille G, Dell'Omo G, Lipp HP (2002) GPS Tracking of foraging Albatrosses. Science 295:1259

Wilson RP, Wilson MPT (1989) Tape: a package-attachment technique for penguins. Wildl Soc Bull 17:77-79

Zar JH (1984) Biostatistical analysis. Prentice-Hall International, London

Submitted: February 1, 2008; Accepted: December 8, 2008

Proofs received from author(s): March 2, 2009 